\title{
EMERGING BRAND MEANINGS IN WEARABLE SPORTS TECHNOLOGY: A CASE STUDY ON SUUNTO SPORTS WATCHES
}

\author{
HILLA KARAMAKI \\ University of Tampere \\ Tampere, Finland \\ hilla.karamaki@gmail.com \\ SONJA LAHTINEN \\ University of Tampere \\ Tampere, Finland \\ sonja.lahtinen@uta.fi \\ PEKKA TUOMINEN \\ University of Tampere \\ Tampere, Finland \\ pekka.tuominen@outlook.com
}

\begin{abstract}
The purpose of this study is to describe and analyse emerging brand meanings in the context of wearable sports technology. The theoretical framework is built on the concept of wearable sports technology and the contemporary literature on brand meanings. This empirical research is based on a case study of the Suunto Ambit3 Sport Sapphire watch. A qualitative projective ZMET-method is applied to generate data from ten interviews with Finnish female customers who own the Suunto Ambit3 Sport Sapphire watch. Eight themes are identified that incorporate several interconnected sub-meanings: well-being, connecting with nature, setting and achieving goals, expressing style, appreciating technological advancement, relying on professionalism, testing one's limits, and embracing special experiences.
\end{abstract}

Key words: Brand Meanings, Wearable Sports Technology, ZMET-method

\section{Introduction}

Wearable sports technology is a relatively new phenomenon, and thus it has not yet been extensively studied in the field of marketing research. As wearable sports technology has several advantages, such as exploiting personal data to support health- and exercise-related 
goals, it can be argued that there is a need to create a better understanding of wearable sports technology also from the consumer's point of view.

Wearable technology is a complex phenomenon, because it integrates characteristics of clothing-related issues, like aesthetics and comfort, and the properties of electronic devices, such as usability. The complexity of wearable technology is only intensified by the collaboration of several stakeholders, such as end-users, engineers, fashion designers, and manufacturers (McCann, 2009). In addition to combining technology- and clothing-related fields, wearable technology is closely connected with the field of health and fitness (Gao et al., 2015). In view of this, the context of wearable sports technology can be defined by three different dimensions: the fields of sports brands, technology, and fashion.

In the context of sports brands, Bouchet et al., (2013) suggest that sports brands should be divided into four dimensions: the functional, the sensorial, the semantic, and the somatic. Most of the elements that these four dimensions consist of can also be found in the brand dimensions of other types of brands, such as luxury brands or technology brands. However, unlike other definitions of brands, sports brands include the somatic dimension, which describes the bodily features. In the case of sports brands, the physical aspect needs to be considered, since bodily experiences while doing sports are an important part of consuming sports brands and the overall brand experience.

In the context of technology consumption, a major stream of research focuses on technology adoption. It discusses consumers' cognitive motivations and behaviour in adopting new technologies (Venkatesh et al., 2012). Researchers have found that users have an increasingly important and interactive role when it comes to the design, development, and marketing of technology brands (Vannoy and Palvia, 2010).

In the context of fashion, consumer behaviour is driven on the one hand by the need to belong to a community, and on the other hand by the need to differentiate oneself from others. According to Han et al., (2010), consumers can manage this need by favouring either prominent or silent branding. In their study on different luxury consumers, they found that depending on the consumers' state of wealth and need for status, consumers either favour the prominent or more discrete visibility of brands to either connect with or differentiate themselves from a specific reference group.

The purpose of this study is to describe and analyse emerging brand meanings in the context of wearable sports technology. Prior research has investigated sports technology brands from the perspective of buyer behaviour and decision-making (Hamann et al., 2007), but only limited research has been conducted from the perspective of brand meaning. Understanding brand meanings is essential for future brand development and marketing strategies within the emerging field of wearable sports technology.

\section{Theoretical Framework for Brand Meanings in Wearable Sports Technology}

\subsection{The Structure and Creation of Brand Meanings}

Brands attach meanings to goods. This can be considered one of the most important functions of branding (Muniz, 1997). According to Batey (2008), the structure of brand meanings can be defined on four levels, reflecting the continuum from tangible, more objective perceptions towards intangible properties that refer to more subjective perceptions. As brand meanings are defined by a smaller group of people, such as a specific culture or sub-culture, the intangible properties become more relevant. On the individual level, brand meanings are subjectively defined, as they emerge from personal experiences with an object, resulting in a personal meaning that varies between individuals (Batey, 2008). 
The division of the tangible and intangible properties of meanings is related to the concept of primary and implicit brand meanings. Primary brand meanings refer to the primary associations and perceptions that immediately come to the consumers' minds concerning a specific brand (Chard, 2013). Implicit brand meanings refer to the psychic resonance that the brand offers to consumers. Implicit brand meanings tend to be more culturally influenced and less category-dependent than primary brand meanings (Chard, 2013).

Traditionally, it has been thought that advertising agencies and brand managers are the creators of brand meanings. The role of the consumer has been seen mainly as the receiver and acceptor of that communicated meaning. However, recently it has become clear that brand meanings are not solely constructed in advertising, but rather in the consumers' minds (First, 2009). The creation of brand meanings should not be thought of as something that only concerns the brand and the consumer. This perspective restricts the role of meaning-makers, leaving out many other parties, such as the institutions and public (Mclnnis et al., 2014).

Ligas and Cotte (1999) suggest that brand meanings are created in three environments. These environments include the marketing environment, the individual environment, and the social environment. The marketing environment acts as the initiator of brand meaning (Malar et al., 2011). In the individual environment, the self-concept influences the creation and nature of brand meanings (Kleine and Kleine, 2000). In the social environment, brand meanings are actively and continuously created and altered between different social entities; the reference groups of these social entities appear to be very important (English and Solomon, 1995). Ligas and Cotte (1999) suggest that brand meanings are created through the interaction of these three environments.

\subsection{The Synthesis of the Theoretical Framework}

The theoretical framework of this study encompasses two different domains. These domains are the context of wearable sports technology and the context of brand meanings. The synthesis of the theoretical framework is based on the interaction between these domains. The synthesis of the theoretical framework is illustrated in Fig. 1. (Karamaki et al., 2018, p. 240). 


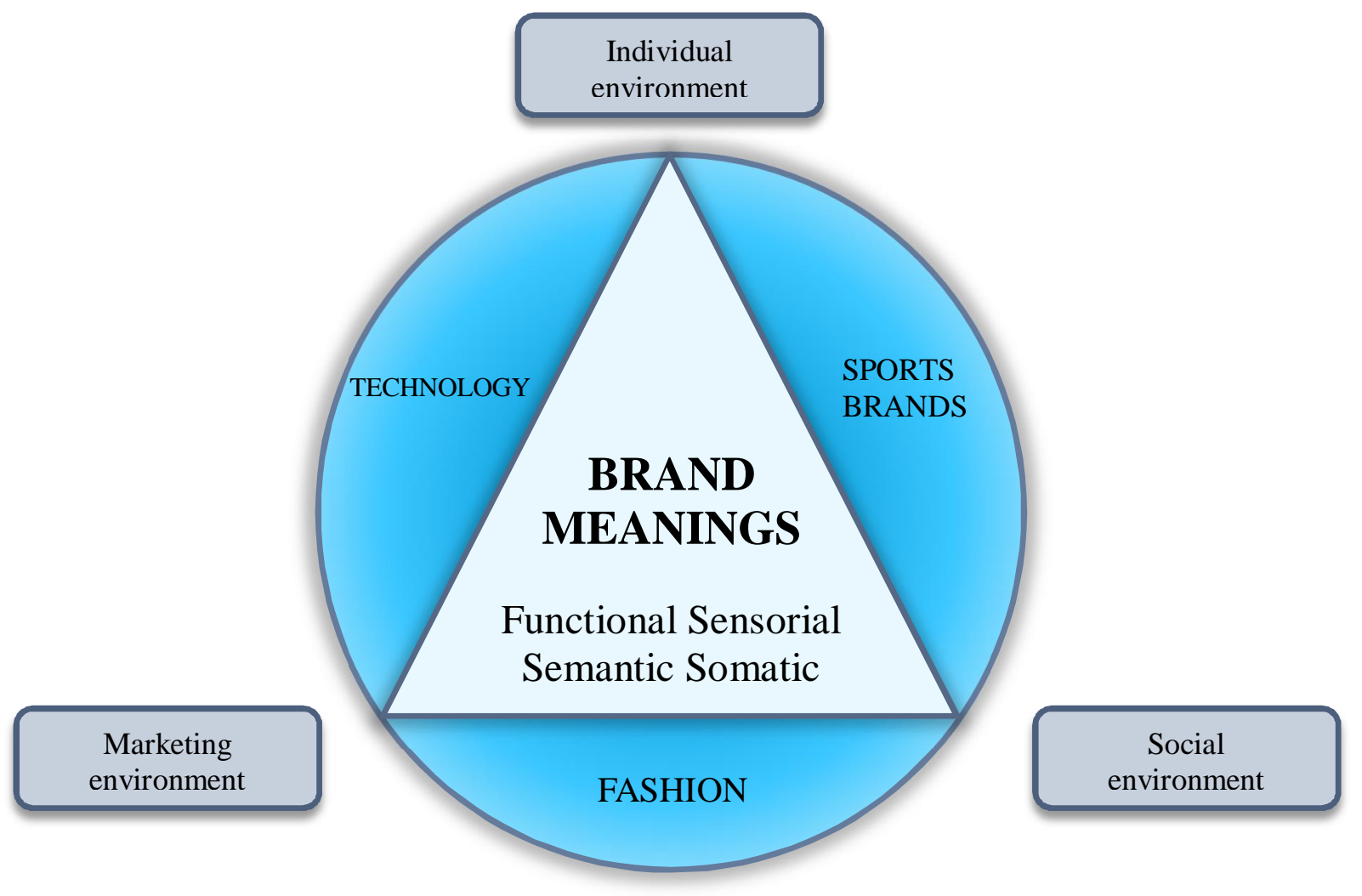

Fig. 1 The synthesis of the theoretical framework (Source: Karamaki et al., 2018, p. 240)

As wearable sports technology products are by definition wearable, it is also essential to consider the fashion aspect in this study. Clothing might be the primarily means of communicating social identity, as it reflects the values of the related social group (Auty and Elliott, 1998).

\section{Conducting the Study}

\subsection{Qualitative Case Study and the Case Company Suunto}

The nature of the research phenomenon should define the most applicable method of inquiry (Silverman, 2005). This study applies qualitative research methods. Qualitative methodology aims to understand complex phenomena in a systematic way, rather than to establish unequivocal causal relationships between single variables (Gummesson, 2005). Thus, qualitative methods are sensitive to the context of the phenomenon and aim to create a holistic understanding of the research topic (Eriksson and Kovalainen, 2016).

In this study, theory and empirical reality are created in a non-linear way where theoretical knowledge and empirical findings take place simultaneously during the phases of data generation and analysis. This type of knowledge-building process is known as the hermeneutical spiral. It refers to a research process in which the researcher moves back and forth from pre-understanding to a higher level of understanding, in this way creating interaction between the already known and what was just learned (Gummesson, 2005).

When seeking a deeper understanding of a specific phenomenon, a case study method is recommended. A case study enables the profound examination of the dynamics of a phenomenon (Yin, 2013). This study aims to understand and produce an interpretation of the phenomenon of wearable sports technology from the customers' perspective. Suunto is an established wearable sports technology company, and it was therefore chosen as a suitable case study company for this study. Suunto is a Finnish company that manufactures sports 
watches, dive computers, and compasses for demanding outdoor sports, and it is known for premium quality technology products that are sold in over 100 countries (Suunto, 2016).

In order to gain a rich insight from the customers of Suunto, one sports watch model and its users were selected as a target group for this study. A premium sports watch model, namely the Suunto Ambit3 Sport Sapphire, was chosen because the model is visually designed to be used also outside sports. The Suunto Ambit3 Sport Sapphire, Suunto's first premium model sports watch specifically for women, was launched in 2014. The Ambit3 Sport Sapphire is an eye-catching multisport GPS watch crafted from premium materials with mobile connection and Ambit3 sport software. Its features include speed, pace, and distance measurement, GPS, route navigation, compass, heart rate tracking also during swimming, and recovery tests among other features (Suunto, 2017).

\subsection{The Zaltman Metaphor Elicitation Technique}

Most of today's marketing research techniques rely on verbal communication as a method of collecting data. However, the consensus among cognitive scientists and communication specialists is that most human communication is nonverbal (Catchings-Castello, 2000). This should also be considered in consumer research. When researchers are pursuing a deeper understanding of consumers' thoughts and feelings, nonverbal research techniques could potentially help to uncover a richer picture of consumers' thinking. To achieve this, marketers need to understand the cognitive structures - or mental models - that affect consumers' feelings and behaviour regarding a specific brand or product (Christensen and Olson, 2002).

The first step towards a better understanding of consumers' mental models is to understand the process of thinking and communication. Neuroscientists know that thoughts typically emerge as images, even though they are expressed verbally (Zaltman and Coulter, 1995). An image is an internal representation used in information processing that is experienced as a conscious thought. Even though verbal language plays an important role in the communication of thoughts, it is not the same as thought (Zaltman, 1997). While thinking is based on images rather than on language, it is also important to enable consumers to represent their thoughts in nonverbal terms. In this way, researchers can get closer to the state in which consumers' thoughts occur and thus be able to learn more about consumer thinking (Zaltman and Coulter, 1995).

Gerald Zaltman developed the Zaltman metaphor elicitation technique (ZMET) in the early 1990s (Christensen and Olson, 2002). ZMET is based on several different fields of research, such as cognitive neuroscience, neurobiology, art criticism, visual anthropology, semiotics, and psycholinguistics. ZMET integrates the visual projection technique, in-depth personal interviews, and qualitative data-processing techniques (Catchings-Castello, 2000).

The key concepts of ZMET include photo-analysis and narration. ZMET allows the participants to collect their own pictures based on specific guidance from the researcher. Having participants collecting their own pictures increases the likelihood that important and previously unrecognised issues will arise from the research (Zaltman, 1997). The application of ZMET consists of four phases: pre-interview, interviews, transcription, and the development of aggregate mental maps (Sugai, 2005). In the first phase, the participants are given a precise description of the research topic and asked to collect typically 8-10 pictures to bring to the interview, which usually takes place one to three weeks later.

The actual interviews consist of several steps (Zaltman, 1997). According to Catchings-Castello (2000), the steps must be modified to support the objectives of the specific research project when necessary. In the first step, storytelling, the participants are asked to describe the content of each picture collected. In the second step, missed images, the 
participants are asked if there was anything that they wanted to include in the pictures, but were not able to find a picture of. Participants are also asked about the relevance of the possibly missing images. In the third step, sorting, the participants sort their pictures into meaningful sets and remove possible duplicates. The fourth step, construct elicitation, is the phase in which the researcher randomly selects three pictures; the participants are asked to combine two of the three pictures and to describe why they are similar and why they differ from the third picture. This process is continued until no new constructs emerge.

\subsection{Data Generation and Analysis}

The research participants were recruited either through an official Facebook advertisement by Suunto (five participants) or by using snowball sampling (five participants), which involved using the researchers' network at Suunto and the contacts of the other interviewees. The Facebook recruitment advertisement was considered a suitable recruitment method since the participants volunteered willingly to participate in the research. Thus, it was expected that these participants would be willing to offer rich and high-quality data for research purposes. However, as this method did not produce enough volunteer participants, the snowball sampling method was used. The participants that were recruited through the Suunto employees' network were either directly asked or had noticed an announcement on Suunto contacts' personal Facebook feed. Altogether ten female owners of the Suunto Ambit3 Sport Sapphire watch were interviewed. The interviewees were all female, since the product under consideration is targeted especially at women. The age of the participants ranged between 32 and 50, with the majority being between 32 and 40 . This matches the age of the average Suunto customer well.

Once all the interviews were completed, all the interview transcripts, tapes, and images were reviewed to identify key themes or constructs and construct pairs. A construct itself has little innate meaning; rather, meanings are acquired through causal associations with other constructs (Zaltman, 1997). In order to find the important constructs that consumers attach to the Suunto Ambit3 Sport Sapphire watch, the analysis was done in two phases. First, individual mental maps were formed, and then they were combined into an aggregated consensus map to represent the collective mental model of the respondents (Christensen and Olson, 2002).

Each interview transcript was coded to represent the thoughts and themes that arose during the interview. According to Zaltman and Coulter (1995), the list of key themes or constructs derived from the examination of the interview transcripts serves as a starting point for the coding process. Once previously unidentified constructs were found during the coding, the construct list was supplemented. This meant that the transcripts were analysed in several rounds, making the coding process yield well-grounded interpretations.

After no more constructs were found, the collective consensus map was formed to understand which constructs were most important to the participants. First, the consensus map represented a mass of constructs and links, but specific constructs or themes were selected for the consensus map based on the number of participants who mentioned them (Zaltman and Coulter, 1995). According to Zaltman (1997), a construct must be mentioned by at least half of the interviewees in order to be included in the consensus map, and the constructs selected for the consensus map should comprise 85 percent of the constructs mentioned by any interviewee.

\subsection{Evaluation of the Research Quality}

The evaluation of the research quality is based on the criteria most often used in qualitative research, namely trustworthiness (Lincoln and Guba, 1985). Trustworthiness can be divided into four domains: dependability, transferability, credibility, and conformability (Eriksson and Kovalainen, 2016). 
Dependability can be determined by evaluating how well the research process is documented. According to Eriksson and Kovalainen (2016), the research should be able to indicate proper traceability and logic in order to obtain transparency. Dependability is valuable as it allows the reader to evaluate the overall quality of the research process (Moisander and Valtonen, 2006). To support the transparency of the research process, all parts of the research - from the emergence of the research purpose, theory development, detailed descriptions of data generation, and the analysis to the detailed description of the situational factor of the research - must be explicitly documented and presented. The ZMET interviews were recorded and transcribed to enable the researchers to return to the data and make the correct analysis.

Transferability refers to showing a connection between the current and previous research (Eriksson and Kovalainen, 2016). The researcher should be able to find similarities between the research - or parts of it - and the already existing literature. Limited similarities between themes that are closely linked with the phenomenon, namely the field of sports brands, technology adoption, and fashion, were found. In addition, some higher-level similarities in fundamental concepts related to the literature and findings concerning brand meaning and related issues were identified.

Credibility refers to the researcher's knowledge of the topic as well as to the sufficient quantity and quality of the data gathered. The researcher needs to be familiar with the research topic, and the presented data must be adequate to support the conclusions (Eriksson and Kovalainen, 2016). This research process started eight months prior to the execution of the first interview, during which the researchers closely familiarised themselves with the phenomenon through literature and media, by attending several essential events, and by discussing the wearable sports products category with relevant sales experts.

Conformability refers to connecting the findings and research interpretations firmly with the data in a way that enables other people to understand them (Eriksson and Kovalainen, 2016). The concept of conformability stems from the postulate of objectivity (Denzin, 1994), but in constructionist research, complete objectivity cannot be achieved as the creation of knowledge is often based on examining subjective perspectives. In addition to the subjective views of the research informants, constructive research is largely based on the interpretation of the researcher. However, conformability requires that the research findings stem from the research informants rather than from the imagination of the researcher (Lincoln and Guba, 1985). To increase conformability in this study, the interpretative findings were closely linked to the empirical data by supplying the reader with a variety of actual quotations.

\section{Brand Meanings in a Wearable Sports Technology Brand}

\subsection{The Eight Empirical Themes of Brand Meanings}

This section discusses the findings of our case study and presents the brand meanings the informants attached to the Suunto Ambit3 Sport Sapphire watch. Eight empirical themes related to brand meanings were identified: well-being, connecting with nature, expressing style, appreciating technological advancement, setting and achieving goals, relying on professionalism, testing ones limits, and embracing special experiences. Each of these eight themes of brand meanings had several sub-meanings and they are next discussed in detail.

\subsubsection{Well-being}

Among sports brands, one of the common aspects of corporate social responsibility is the promotion of health-related initiatives (Bouchet et al., 2013). Each interviewee brought up the theme of well-being during the interview, which reflects the tendency of valuing a healthy lifestyle. The brand meaning of well-being consisted of two sub-meanings: physical well-being and mental well-being. Both of these sub-meanings are highly constructed through bodily 
experiences and behaviours, such as physical exercise or the bodily experience of endorphins and well-being, as described by some participants. Thus, as suggested in previous research, the dimension that is typical for sports brands, namely the somatic dimension (Bouchet et al., 2013), was also identified in this study.

\subsubsection{Connecting with Nature}

The theme of nature was very prominent in the meanings the participants connected with the Suunto Ambit3 Sport Sapphire watch. Every participant mentioned nature, and several participants had selected the majority of their pictures to depict nature scenery or outdoor sports.

Previous marketing research has described connecting with nature as a romantic idea that helps consumers escape the hectic pace of modern life (Arnould, 2007). Furthermore, romantic writers and artists have embraced nature as an organic, fertile, and mystical force that people can visit to recover from stress (Thompson, 2004). These notions could also be found in the empirical data of this study. Nature seemed to play an integral role in the participants' hobbies. Several participants also mentioned sports like downhill skiing, cycling, or climbing, which are closely linked to the element of nature.

The brand meaning of connecting with nature comprised several sub-meanings. The sub-meanings of relaxation, escaping stress, and taking time for yourself represent the traditional romantic relationship towards nature where nature is seen to have healing power and help individuals to reconnect with themselves. On the other hand, the sub-meanings of adventure, overcoming the challenges of nature, and enjoying life are more dynamic, representing excitement and action.

\subsubsection{Setting and Achieving Goals}

The very feature that makes the watch a piece of wearable sports technology - the ability to measure sports-related data - was brought up throughout the data and linked together with several sub-meanings, such as analysing the data, gaining motivation through the data, improving oneself, and setting and achieving goals. For several participants, measuring the data seemed to have an instrumental value in supporting their motivation and goals, but to some participants the data itself also seemed to be valuable. Regardless of whether measuring data was seen as a valuable brand meaning in itself or as an instrumental meaning, it was perceived as a very important meaning related to engaging in sports.

The brand meaning of setting and achieving goals consisted of four highly interconnected sub-meanings. The meaning of setting and achieving goals builds on the tangible benefit of the product, namely data measurement and analysis. Thus, it could be argued that setting and achieving goals is rooted in the functional dimension (Bouchet et al., 2013) of the Suunto Ambit3 Sport Sapphire watch. The functional benefits of the product helped the participants to be their own coaches, to motivate themselves, and to set and achieve exercise-related goals. It could be said that the functional features of the watch served as a mental coach, which represents the deeper metaphor of achievement through work and improving oneself.

\subsubsection{Expressing Style}

Possessions can be used to satisfy one's psychological needs, such as creating one's self-concept, expressing self-identity, and allowing one to differentiate oneself from others (Escalas and Bettman, 2005). Possessions can also serve a social purpose, reflecting one's ties to, e.g., cultural groups and communities, which can include brand communities and thus 
also leisure-related communities (Muniz and O'Guinn, 2001). The participants confirmed that through using the Suunto Ambit3 Sport Sapphire watch, they could express their style and thereby create and communicate their self-concept, thus also connecting themselves with others that share a similar style and interests. Several participants had collected pictures representing style and accessories. It is apparent that in addition to the benefits of the technology embedded in the watch, the participants view the watch as a style piece that communicates specific messages about the wearer.

The empirical data revealed several sub-meanings in the brand meaning of expressing style. The various aspects of style that the participants saw the watch as representing - high quality, luxury, sportiness, trendiness, and modernity - all together appeared to make the watch a statement of taste and lifestyle. As meaningful communication enables consumers to connect with desired social groups (Ligas and Cotte, 1999), through wearing the watch, the participants were able to make a statement and connect with other, similar people. What seemed to make the watch desirable in terms of style was the fact that all these aspects were brought together.

\subsubsection{Appreciating Technological Advancement}

Several participants mentioned the watch's technology during the interviews. It was apparent that the participants connected the watch with an image of high quality technology and progressiveness. The technological qualities of the product could be connected closely to the functional dimension of the product, as they present the functionality, quality, and durability of the product (Wiedmann et al., 2007).

The brand meaning of appreciating technological advancement was constructed around three sub-meanings. The sub-meanings of believing in the potential of technology and valuing the ideal of advancement represent the more abstract level of appreciation, whereas valuing useful innovation, such as making things more convenient, represents a more tangible aspect of the brand meaning.

\subsubsection{Relying on Professionalism}

Several participants brought up the matter of professionalism. The brand meaning of professionalism contains different aspects: safety, intelligent technology, extreme environments, and professional athletes. The meaning of professionalism seemed to make the participants feel good about their purchase and their connection with the Suunto brand.

The brand meaning of relying on professionalism consisted of four sub-meanings: valuing high quality, looking up to professionals, considering safety issues, and appreciating challenging environments. Somewhat similarly to the brand meaning of expressing style, the brand meaning of relying on professionalism also reflects the symbolic and expressive dimension of the brand (Bouchet et al., 2013).

\subsubsection{Testing One's Limits}

Training and doing different kinds of sports was prominently the most discussed issue during the interviews, as almost all the participants had collected sports-related pictures. Several participants talked about heavy exercise and pushing one's limits during training. This image of challenging oneself and excelling was seen as an important mental and physical goal related to training and sports activities. Overcoming challenges could be seen as an important brand meaning that the participants also connected with the Suunto sports watch. 
The brand meaning of testing one's limits comprises four highly interconnected sub-meanings, and is fundamentally connected with the brand meaning of appreciating technological advancement, as both meanings share the orientation towards achievement and excellent performance. However, unlike in the technology aspect, testing one's limits is more of a mental and behavioural orientation, whereas the technology aspect relies more on the functionality and performance of the device. Testing one's limits also seemed to be appreciated as a philosophy or an orientation towards life. By having the attitude of testing one's limits, participants could seemingly build their sense of self as achievers.

\subsubsection{Embracing Special Experiences}

Throughout the empirical data, it was evident that some of the participants seemed to value some moments, occasions, and experiences over others. While participants discussed their experiences, there was a clear line between ordinary training and experiences and special sporting moments like competitions or other activities. During the interviews, the participants brought up experiences they had enjoyed regardless of how strongly the experiences were sports-related. The majority of the experiences the participants brought up and highlighted were somehow special, but also ordinary training moments in nature were described with enthusiasm.

The brand meaning of embracing special experiences was constructed upon four sub-meanings. According to Bouchet et al., (2013), brands can act as experience producers, and thus it is obvious that here the brand meaning of embracing special experiences reflects the sensorial and experiential dimension. The special experiences that the participants embraced comprised a combination of the elements of mental and physical well-being, connecting with nature, achieving goals, and testing one's limits.

\subsection{Re-evaluation of the Theoretical Framework}

The synthesis of the re-evaluated theoretical framework in this study suggests that the concept of wearable sports technology consists of three main domains: the field of technology, the field of sports brands, and the field of fashion. In light of the empirical findings, these three fields combined serve as an applicable context that characterises the field of wearable sports technology. This evaluation stems from the fact that among the brand meanings, the participants attached brand meanings to the Suunto Ambit3 Sport Sapphire watch such as appreciating technological advancement (technology), setting and achieving goals, testing one's limits, well-being, connecting with nature (sports), and expressing style (fashion). Fig. 2 illustrates the re-evaluated theoretical framework (originally created by Karamaki et al., 2018) with eight empirical themes of brand meanings based on our case study. 


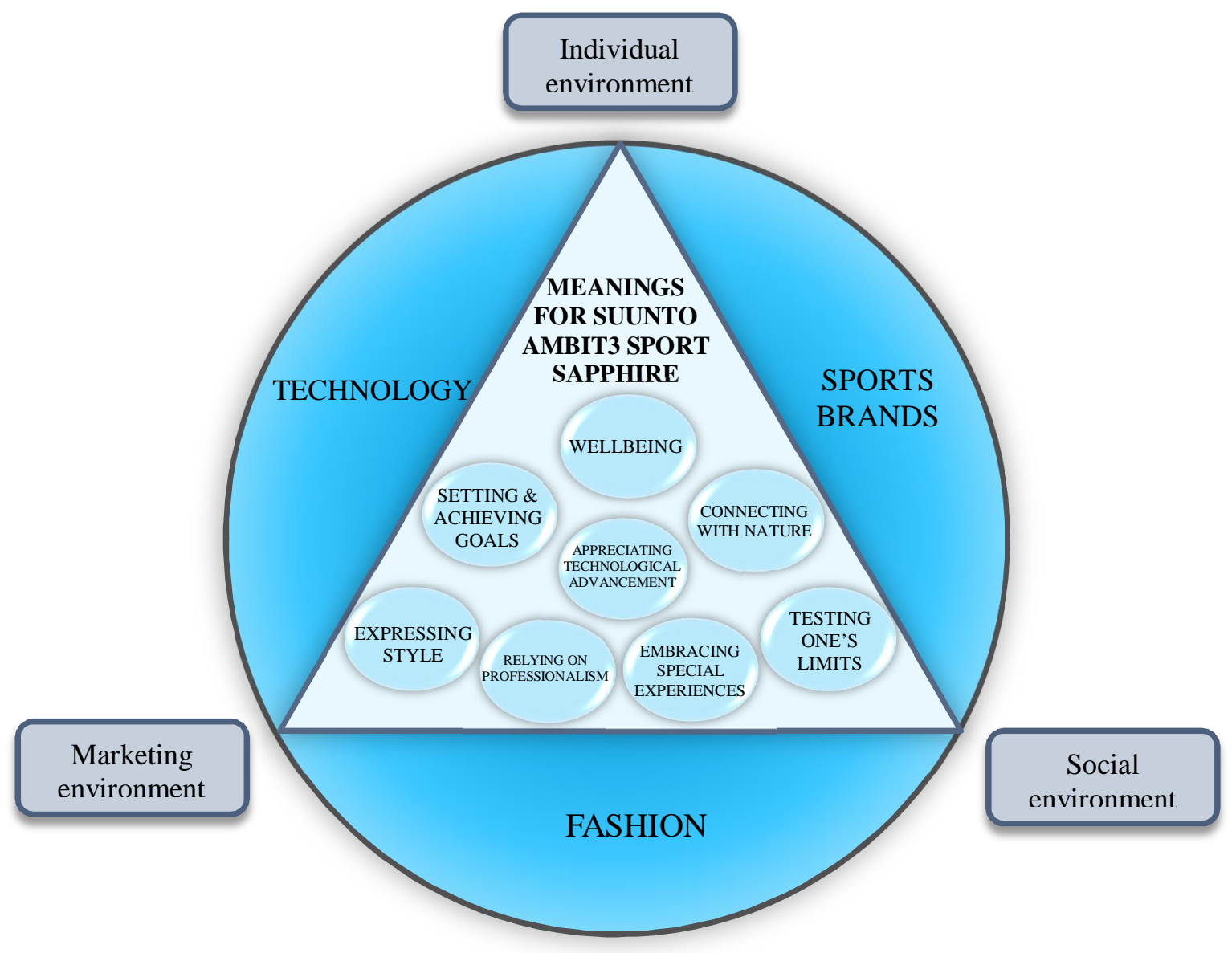

Fig. 2 The re-evaluated theoretical framework (Source: Karamaki et al., 2018, p. 240 and empircal findings from this case study)

As Suunto represents sports brand, the theoretical framework predicted that the brand meanings would reflect the four dimensions typical for sports brands: the functional, the sensorial, the semantic, and the somatic. This view was supported by the empirical research findings, as every predicted dimension was found in the brand meanings. The functional dimension was represented in the brand meaning of setting and achieving goals and the sub-meanings of measuring and analysing data, appreciating technological advancement, valuing high technology, and valuing useful innovation. The sensorial dimension was reflected in the brand meaning of embracing special experiences and sub-meanings of connecting with nature - e.g. through relaxation - taking time for yourself, and admiring challenging environments. Considering the semantic dimension, all brand meanings seemed to have expressive and symbolic features, especially the brand meaning of expressing style. Considering the somatic dimension that is uniquely typical for sports brands, the brand meanings of well-being and testing one's limits reflected the somatic dimension, as the participants frequently described bodily behaviours, i.e. training.

Altogether eight interconnected brand meanings were attached to the Suunto Ambit3 Sport Sapphire watch. These brand meanings were well-being, connecting with nature, setting and achieving goals, expressing style, appreciating technological advancement, relying on professionalism, testing one's limits, and embracing special experiences. Three of these brand meanings were clearly emphasised throughout the data - namely setting and achieving goals, well-being, and connecting with nature.

\section{Discussion and Concluding Remarks}




\subsection{Theoretical Contribution}

Scientific research should always add to the already existing body of knowledge in some way. To make a theoretical contribution, research should provide new information and explanations on theory, methodology, or context (Ladik and Steward, 2008). This study concentrated on examining the emerging field of wearable sports technology brands from a new perspective, and, therefore, produced a mainly methodological and contextual contribution.

A methodological contribution can be generated by constructing and testing a new method, by altering an old method, or by using a method in a context that has not been examined using that method before (Ladik and Steward, 2008). This study applied the Zaltman metaphor elicitation technique (ZMET) in the context of a wearable sports technology brand. Such brands have earlier been investigated mainly from the perspective of buyer behaviour and decision-making (Hamann et. al., 2007), but little research has been conducted to investigate the brand meanings consumers attach to wearable sports technology brands. This study contributed methodologically, as it qualitatively examined the meanings consumers attach to a wearable sports technology brand and to a specific model - the Suunto Ambit3 Sport Sapphire - by applying ZMET.

The contextual contribution refers to adding to the existing knowledge about a specific context (Ladik and Steward, 2008). Here, the contextual contribution was achieved as the study concentrated on examining the emerging phenomenon of wearable sports technology brands. This field of inquiry has not yet received much attention within academic marketing research, despite the obvious call for it. This study added to the knowledge and understanding of what kinds of meanings consumers can attach to wearable sports technology brands.

\subsection{Managerial Implications}

Marketing research should also always seek to offer useful insights to practitioners. This study examined the context of wearable sports technology that has until now attracted surprisingly little attention from the perspective of consumer research. In addition to offering valuable information to Suunto, the findings of this study provide valuable insights into how consumers perceive wearable sports technology brands in the larger market of wearable sports technology. The following observations can be utilised both in product development and in branding and marketing strategies.

First, attention to the ways marketing research is conducted should closely considered. In order to gain a deeper and more insightful understanding of consumer perceptions and behaviour, researchers must engage managers and customers more actively in the research process by enabling them to fully present their thinking (Zaltman, 1997). Accessing the underlying themes and values behind consumer thinking helps marketers to better understand the motivations behind consumer behaviour. Traditionally, marketing research has concentrated on using linguistic techniques, but it has been found that thinking is actually based on images rather than words (Zaltman, 1997). The usage of images to gain empirical data might help to generate a fuller understanding of consumer thinking. Therefore, we propose that projective ZMET be used in conveying consumers' subconscious thinking.

This study revealed eight thematic brand meanings that female customers of Suunto attach to the Suunto Ambit3 Sport Sapphire watch. These meanings can help marketers and product development to better understand the themes that are important to female consumers within the wearable sports technology field. It should be noted that the themes that arose from this study in the form of varying brand meanings are self-expressive in nature, and would rate highly in a hierarchy of products of mere necessity versus products with symbolic value. Furthermore, the variety of different brand meanings is worthy of note. We suggest that 
marketers of wearable sports technology brands evaluate whether their strategic portfolio incorporates the full potential of all these brand meanings. Next, to offer some reference ideas, some selected brand meanings are briefly analysed from the perspective of practical implications.

The theme of luxury emerged though the brand meaning of expressing style. Some participants saw this as an admirable thing, while others found it did not fit the desired simple style they were keen to express. Thus, there might be more varying needs and desires in the form of niches or segments within the female target market that marketers could identify and thus develop better-targeted wearable sports technology products and brands.

Another possibly insightful implication might lie in the brand meaning of well-being. In addition to physical well-being, mental well-being was also emphasised as an important aspect that the female consumers linked to the overall brand meaning of well-being. Thus, it might be valuable to scrutinise the possible activities and features that would incorporate the mental aspect of well-being into the product. Mental well-being could also be emphasised in branding and marketing activities.

Connecting with nature emerged as an important brand meaning that incorporated several aspects in the form of sub-meanings. Connecting with nature incorporated both a relaxing aspect and a challenging aspect. Regardless of the aspect, nature seemed to have a central role in how the participants viewed the Suunto Ambit3 Sport Sapphire watch. Therefore, marketers should consider whether they are exploiting the metaphors linked to nature to their fullest potential in their current marketing. In this study, nature seemed to call for deeper metaphors of adventure or relaxation. We advise that the metaphors linked to nature are thoroughly exploited in marketing and branding, e.g., by the means of storytelling or experiential marketing.

The brand meaning of relying on professionalism seemed to be rooted in the heritage of the Suunto brand. Suunto was seen as a reliable and ultimately high performance brand. This image seemed to rest on perceptions of the challenging environments in which Suunto products can be used. For example, the heritage of the diving products seemed to extend the high-quality image to cover the whole brand and product range, even the models that did not actually incorporate such features. Therefore, we suggest that images of these challenging environments, which are linked to the brand and emphasise the dependability and performative aspects, should be exploited more in the branding strategy.

\subsection{Further Research Directions}

Wearable sports technology is an emerging and continuously growing field that has not received much attention within marketing research. It is obvious that it needs to be studied further. It is important to examine the meanings consumers attach to wearable sports technology brands more closely. Wearable sports technology products are the first technology product category that people are continuously wearing, which also makes the phenomenon an interesting topic for researchers. The brand meanings consumers attach to wearable sports technology should be studied in order to produce a more in-depth understanding upon which marketers can develop the products and related marketing strategies.

It must be noted that this study has its limitations and therefore leaves much space for further research. Firstly, this specific study concentrated on one specific brand model, the Suunto Ambit3 Sport Sapphire watch, which is especially designed for women. In order to gain a more versatile understanding, it would be necessary to conduct research with informants of both genders. As technology has traditionally been considered more masculine in nature, it would 
be interesting to see whether there are gender differences in brand meanings associated with wearable sports technology.

Secondly, the age of the participants of this study ranged from 32 to 50 years. It would be interesting to examine whether younger consumers attach different meanings to wearable sports technology brands, as the younger generation has already been familiarised with technology since childhood. Thirdly, this study consisted of informants located only in Finland. Therefore, it would be valuable to generate a more international perspective by studying consumers from other geographical locations. If such studies are conducted, we suggest that the socio-economic atmosphere be taken into consideration, as the meanings attached might vary among countries and areas. People living in a technology-affirmative atmosphere, such as in larger cities and developed countries, might attach different meanings to wearable sports technology products than people living in rural or remote areas. This might affect the values and features consumers are looking for in wearable sports technology products and brands.

Finally, this study concentrated on brand meanings attached to a premium watch model, the Suunto Ambit3 Sport Sapphire. The market for wearable sports technology includes products of different levels of quality and with different brand images. Therefore, it would be insightful to examine brand meanings related to other product or model categories determined by how prestigious or high quality they are intended to be by the manufacturer and how they are perceived by consumers.

\section{References}

Arnould, E., 2007. Should consumer citizens escape the market? The Annals of the American Academy of Political and Social Science, 611(1), pp. 96-111.

Auty, S., and Elliott, R., 1998. Fashion involvement, self-monitoring and the meaning of brands. Journal of Product and Brand Management, 7(2), pp. 109-123.

Batey, M., 2008. Brand meaning. New York: Routledge.

Bouchet, P., Hillariet, D., and Bodet, G., 2013. Sport brands. New York: Routledge.

Catchings-Castello, G., 2000. The ZMET alternative. Marketing Research, 12(2), pp. 6-12.

Chard, C., 2013. Understanding the brand meaning of the Canadian interuniversity sport hockey league: An insurance policy if all else fails! Sport in Society, 16(3), pp. 327-339.

Christensen, G., and Olson, J., 2002. Mapping consumers' mental models with ZMET. Psychology and Marketing, 19(6), pp. 477-502.

Denzin, N., 1994. The art and politics of interpretation. In: N., Denzin, and Y., Lincoln, (eds.) Handbook of qualitative research. Thousand Oaks: Sage, pp. 500-515.

English, B., and Solomon, M., 1995. To be and not to be: Lifestyle imagery, reference groups, and the clustering of America. Journal of Advertising, 24(1), pp. 13-28.

Eriksson, P., and Kovalainen, A., 2016. Qualitative methods in business research. London: Sage.

Escalas, J., and Bettman, J., 2005. Self-construal, reference groups and brand meaning. Journal of Consumer Research, 32(6), pp. 378-389.

First, I., 2009. Brand meaning and its creation in a cross-cultural context. Academic dissertation, St. Gallen: Publications of University of St. Gallen.

Gao, Y., Li, H., and Luo, Y., 2015. An empirical study of wearable technology acceptance in healthcare. Industrial Management and Data Systems, 115(9), pp. 1704-1723. 
Gummesson, E., 2005. Qualitative research in marketing. A road-map for a wilderness of complexity and unpredictability. European Journal of Marketing, 39(3/4), pp. 309-327.

Hamann, D., Williams, R., and Omar, M., 2007. Branding strategy and consumer high technology product. Journal of Product and Brand Management, 16(2), pp. 98-111.

Han, Y., Nunes, J., and Dréze, X., 2010. Signaling status with luxury goods: The role of brand prominence. Journal of Marketing, 74(4), pp. 15-30.

Karamaki, H., Lahtinen, S., and Tuominen, P., 2018. Building a conceptual model for brand meanings in wearable sports technology. In: M.H., Bilgin, H., Danis, E., Demir and U., Can (eds.) Eurasian Business Perspectives, Eurasian Studies in Business and Economics 8/1. Cham, Springer International Publishing, pp. 233-243.

Kleine, R., and Kleine, S., 2000. Consumption and self-schema changes throughout the identity project life cycle. Advances in Consumer Research, 27(1), pp. 279-285.

Ladik, D., and Stewart, D., 2008. The contribution continuum. Journal of the Academy of Marketing Science, 36(2), pp. 157-165.

Ligas, M., and Cotte, J., 1999. The process of negotiating brand meaning. Advances in Consumer Research, 26(1), pp. 609-614.

Lincoln, Y., and Guba, E., 1985. Naturalistic inquiry. London: Sage.

Malar, L., Krohmer, H., Hoyer W. D., and Nyffenegger B., 2011. Emotional brand attachment and brand personality: The relative importance of the actual and the ideal self. Journal of Marketing, 75(4), pp. 35-52.

McCann, J., 2009. End-user based design of innovative smart clothing. In: J., McCann, and D., Bryson (eds.) Smart Clothes and Wearable Technology. Boca Raton: CRC Press, pp. 424.

Mclnnis, D., Whan Park, C., and Priester, J., 2014. Handbook of brand relationships. New York: Routledge.

Moisander, J., and Valtonen, A., 2006. Qualitative marketing research: A cultural approach. London: Sage.

Muniz, A., 1997. Consumers and brand meaning: Brands, the self and others. Advances in Consumer Research, 24(1), pp. 308-310.

Muniz, A., and O'Guinn, C., 2001. Brand community. Journal of Consumer Research, 27(4), pp. 412-431.

Silverman, D., 2005. Doing qualitative research: A practical handbook. London: Sage.

Sugai, P., 2005. Mapping the mind of the mobile consumer across borders. An application of the Zaltman Metaphor Elicitation Technique. International Marketing Review, 22(6), pp. 641657.

Suunto, 2016. Suunto sports watches, [online] Available at: <http://www.suunto.com/en-GB> [Accessed 2 December 2016].

Suunto, 2017. Suunto Ambit3 Sport Sapphire, [online] Available at: <http://www.suunto.com/en-GB/Products/sports-watches/Suunto-Ambit3-Sport/Suunto-

Ambit3-Sport-Sapphire> [Accessed 2 February 2017].

Thompson, C., 2004. Marketplace mythology and discourses of power. Journal of Consumer Research, 31(1), pp. 162-180.

Vannoy, S. A., and Palvia, P., 2010. The social influence model of technology adoption. Communications of the ACM, 53(6), pp. 149-153. 
Venkatesh, V., Thong, J., and Xu, X., 2012. Consumer acceptance and user of information technology: Extending the unified theory of acceptance and use of technology. MIS Quarterly, 36(1), pp. 157-178.

Zaltman, G., 1997. Rethinking market research: Putting people back in. Journal of Marketing Research, 34(4), pp. 424-437.

Yin, R., 2013. Case study research. Design and methods. Thousand Oaks: Sage.

Zaltman, G., and Coulter, R., 1995. Seeing the voice of the customer: Metaphor-based advertising research. Journal of Advertising Research, 35(4), pp. 35-51. 